\title{
EMPREGO DE PREBIÓTICO EM DOCE DE LEITE BUBALINO VISANDO À REDUÇÃO DA SACAROSE
}

\author{
Alice Espíndola Moreira Cardoso ${ }^{1}$, Luiza Medeiros Cardoso $^{1}$, Silvani Verruck ${ }^{2}$, Maria Helena \\ Machado Canella ${ }^{2}$ e Elane Schwinden Prudencio ${ }^{3}$ \\ ${ }^{1}$ Universidade Federal de Santa Catarina, Departamento de Ciência e Tecnologia de Alimentos, \\ Graduada em Ciência e Tecnologia de Alimentos \\ ${ }^{2}$ Universidade Federal de Santa Catarina, Departamento de Ciência e Tecnologia de Alimentos, \\ Mestre em Ciência dos Alimentos \\ ${ }^{3}$ Universidade Federal de Santa Catarina, Departamento de Ciência e Tecnologia de Alimentos, \\ Doutora em Ciência dos Alimentos, \\ E-mail para contato: elane.prudencio@ufsc.br
}

\begin{abstract}
RESUMO - O objetivo deste trabalho foi verificar o efeito da substituição parcial da sacarose pela oligofrutose nas propriedades físico-químicas, de cor e de textura do doce de leite produzido com leite de búfala. Assim, primeiramente foram determinadas as propriedades físico-químicas do leite, e na sequência o mesmo foi utilizado para elaborar os doces de leite de búfala. Dos doces de leite foi determinado o rendimento, suas propriedades físico-químicas, de cor e de textura. Ao final verificou-se que o rendimento e os valores do $\mathrm{pH}$ foram maiores para o doce de leite de búfala com oligofrutose. A oligofrutose não influenciou sobre o teor de sólidos solúveis totais, acidez, umidade, atividade de água e sais minerais do doce de leite de búfala. $\mathrm{O}$ uso da oligofrutose contribuiu para a obtenção de um doce de leite mais escuro, mas foi observado um predomínio da cor amarela em todos os doces elaborados. Por fim, a adição de oligofrutose contribuiu para obtenção de um doce de leite de búfala mais firme, mais adesivo e que requer maior energia para ser mastigado.
\end{abstract}

Palavras-chave: Derivado lácteo. Substituição de açúcar. Oligofrutose. Propriedades físico-químicas.

DOI: $10.5965 / 24473650412018001$

\section{INTRODUÇÃO}

O leite de búfala oferece importante valor nutritivo e excelente rendimento na preparação de seus derivados devido ao seu elevado teor de gordura, proteína, sólidos totais e minerais (PATIÑO, 2011; SENO, 2007). De acordo com a International Dairy Federation (2012) o leite de búfala (Bubalus bubalis) é o segundo tipo de leite mais consumido no mundo com uma produção anual de aproximadamente 97 milhões de toneladas, ficando atrás somente do leite de vaca. A produção leiteira das búfalas é considerada de grande importância em vários países 
Recebido em:

$19 / 06 / 2018$

Aceito em:

$09 / 10 / 2018$

(AMARAL, 2005), incluindo o Brasil. Segundo dados do Ministério da Agricultura, Pecuária e Abastecimento em 2018, o efetivo do rebanho bubalino no Brasil era igual a 1.351.631cabeças (BRASIL, 2018). No Brasil, a partir deste leite são produzidos tradicionalmente queijos como a muçarela e os frescais (BUZI et al., 2009). Desta forma, doce de leite de búfala seria um produto inovador.

Um dos produtos lácteos mais consumidos na América do Sul é o doce de leite (DEMIATE et al., 2001). O doce de leite é um produto tipicamente latino-americano, característico dos países como Brasil, Chile, principalmente Uruguai e Argentina, sendo, no entanto produzido em larga escala com leite bovino (VIEIRA et al., 2011).

O doce de leite é um produto obtido pela concentração de leite adicionado de sacarose, que adquire coloração, textura e sabor próprio em consequência das reações de escurecimento não

enzimático, sendo muito apreciado pelos consumidores. É usado como ingrediente para a preparação de alimentos como bolos, biscoitos, sorvetes, além de ser consumido diretamente na alimentação como sobremesa ou acompanhamento (DEMIATE et al., 2001). Yãnéz et al. (2018) relataram que a diversidade de ingredientes e suas incorporações em doce de leite, vem satisfazer às condições do mercado atual, como os capazes de beneficiar a saúde do consumidor. Assim, a substituição parcial da sacarose pela oligofrutose no processamento de doce de leite poderia contribuir para o desenvolvimento de um alimento saudável. Entretanto, as características desse doce de leite devem ser similares aos tradicionais.

Desta forma, além do caráter inovador, a avaliação do efeito do uso da oligofrutose como substituto parcial de sacarose nas propriedades de doce de leite, usando leite de búfala como matéria-prima, se justificaria. Além disso, teriam também resultados científicos referentes ao protocolo de processamento e às características físico-químicas, de cor e de textura desse produto inovador. Sendo assim, o objetivo deste trabalho foi verificar o efeito da substituição parcial da sacarose pelo prebiótico oligofrutose nas propriedades físico-químicas, de cor e de textura do doce de leite produzido com leite de búfala.

\section{MATERIAL E MÉTODOS}

\subsection{Material}

$\mathrm{Na}$ elaboração dos doces de leite foi utilizado leite de búfala integral pasteurizado, o prebiótico oligofrutose (Orafti® P95, Orafti, Tienen, Bélgica) com o grau de polimerização entre 2 e 8, sacarose (açúcar refinado Caravelas ${ }^{\circledR}$, São Paulo, Brasil), bicarbonato de sódio premium (Certa Ind. e Com. de Alimentos Ltda, São Paulo, Brasil), glicose e açúcar invertido (Karo®, Unilever, São Paulo, Brasil). Todos os reagentes empregados foram de grau analítico.

\subsection{Caracterização física e química do leite de búfala}

O teor de sólidos totais $(\mathrm{g} / 100 \mathrm{~g})$ foi determinado através do método gravimétrico por secagem em estufa a $105{ }^{\circ} \mathrm{C}$ até obter peso constante. $\mathrm{O}$ teor de proteína foi verificado através do método de Micro-Kjedahl ( $\mathrm{N}$ x 6,38) (AOAC, 2005) Para determinar o teor de lipídeos foi usado o método butirométrico proposto por Gerber. $\mathrm{O}$ teor de sais minerais foi analisado por método 
Recebido em:

$19 / 06 / 2018$

Aceito em:

$09 / 10 / 2018$

gravimétrico, utilizando carbonização em mufla à $550{ }^{\circ} \mathrm{C}$ por 4 horas, enquanto a acidez titulável foi determinada em $\mathrm{g} / 100 \mathrm{~g}$ de ácido lático (IAL, 2008). O pH foi determinado por meio do pHmetro (BEL Engenharia, W38 Monza, Itália). Todas estas análises foram realizadas em triplicata.

\subsection{Elaboração do doce de leite}

Foram produzidos dois doces de leite utilizando leite de búfala integral pasteurizado como matéria-prima, conforme descrito por Pieretti (2012). Na primeira formulação (B1) foram utilizados leite de búfala integral; $20 \mathrm{~g} / 100 \mathrm{~g}$ de sacarose; $2 \mathrm{~g} / 100 \mathrm{~g}$ de glicose; e adicionado bicarbonato de sódio até atingir a acidez de $13^{\circ} \mathrm{D}$ (correspondendo a $0,13 \mathrm{~g}$ de ácido lático por $100 \mathrm{~mL}$ de leite de búfala), a fim de atingir a acidez ideal para a fabricação do doce de leite. Na segunda formulação (B2) houve a substituição parcial de sacarose $(10 \mathrm{~g} / 100 \mathrm{~g})$ por oligofrutose (10 g/100g), enquanto as quantidades dos demais ingredientes não foram modificadas. Cada doce de leite foi elaborado de acordo com o procedimento tradicional de fabricação, ou seja, empregando um tacho aberto em pressão atmosférica, em ebulição, e com agitação constante, até atingir o teor de sólidos solúveis aproximado de $70^{\circ}$ Brix (SILVA et al., 2015). Depois de atingir a concentração desejada, foi realizado o resfriamento a $70{ }^{\circ} \mathrm{C}$, o envase em embalagens plásticas seladas com tampas de folha de alumínio (Sulpack®, Rio Grande do Sul, Brasil), que foram mantidas em temperatura ambiente até a realização das análises. Todas as duas formulações (B1 e B2) foram realizadas triplicata.

\subsection{Rendimento}

O rendimento dos doces de leite elaborados foi obtido através da Equação 1, onde m1 é a massa obtida de doce de leite em gramas após a fabricação, e m2 é o somatório da massa de leite de búfala e as massas dos demais ingredientes utilizados na elaboração do doce de leite (OLIVEIRA et al., 2016).

$\operatorname{RENDIMENTO}(\%)=(\mathrm{m} 1 / \mathrm{m} 2) \times 100$

\subsection{Caracterização física e química do doce de leite}

As amostras de doces de leites (B1 e B2) foram analisadas quanto ao teor de sólidos solúveis totais ( ${ }^{\circ}$ Brix) utilizando refratômetro (Mettler Toledo - Quiuck-Brix90 LLI58318, Barueri, SP). O pH das amostras de doce de leite foi determinado utilizando-se o método potenciométrico por meio de pHmetro (BEL Engenharia, W38 Monza, Itália).

A acidez foi determinada por titulometria com solução de hidróxido de sódio $(\mathrm{NaOH}) 0,1 \mathrm{~N}$ utilizando-se, como indicador $\mathrm{pH}$ em torno de 8,3, em conformidade com a metodologia descrita no Manual de Normas Analíticas do Instituto Adolfo Lutz. O teor de sais minerais (g/100g) dos doces de leite foi determinado utilizando mufla a $550{ }^{\circ} \mathrm{C}$ por 4 horas (IAL, 2008). O teor de umidade $(\mathrm{g} / 100 \mathrm{~g})$ das amostras foi avaliado através de secagem em estufa a $105{ }^{\circ} \mathrm{C}$ até peso constante (AOAC, 2005). A atividade da água dos doces de leite foi medida a $25^{\circ} \mathrm{C}$, utilizando o analisador Aqualab 4TE (Decagon Devices, EUA), após as amostras terem sido estabilizadas 
Recebido em:

$19 / 06 / 2018$

Aceito em:

$09 / 10 / 2018$

durante 15 minutos. A análise da cor das amostras de doce de leite foi determinada utilizando colorímetro (Minolta Chroma Meter CR-400, Osaka, Japão), regulado para operar com iluminante D65 e ângulo de observação de $10^{\circ}$, previamente calibrado. Foi utilizada para calcular os parâmetros $L^{*}$ e $b^{*}$ da escala de cor CIELab. O parâmetro $L^{*}$ varia de $0-100$, indicando a variação de cor de preto para branco; enquanto o eixo $b^{*}$ mostra a variação de amarelo $\left(+b^{*}\right)$ para azul (-b). Todas estas análises foram realizadas em triplicata.

A análise do perfil de textura foi realizada utilizando-se o texturômetro Stable Micro Systems, modelo TA.HD.plus acompanhado pelo programa Exponente versão 6.1.1.0. Nesta medição foram empregados os seguintes parâmetros: velocidade de teste de $2,0 \mathrm{~mm} / \mathrm{s}$; distância de 10,0 mm; altura de $20 \mathrm{~mm}$ e um corpo de prova (probe) de alumínio de $490 \mathrm{~mm}$. Da curva de TPA foram obtidos os seguintes parâmetros: firmeza $(\mathrm{N})$, elasticidade, adesividade (N.s) e gomosidade $(\mathrm{N})$. Todas estas medidas foram realizadas cinco vezes empregando diferentes embalagens de doce de leite bubalino.

\subsection{Análise estatística}

Para determinar diferenças significativas $(\mathrm{P}<0,05)$ entre todas as amostras foi utilizada a análise de variância (ANOVA) seguida pelo teste de Tukey, utilizando o software STATISTICA 13.3 (StatSoft Inc., Tulsa, EUA). Todos os resultados foram expressos como média \pm desvio padrão.

\section{RESULTADOS E DISCUSSÃO}

\subsection{Caracterização física e química do leite de búfala}

A Tabela 1 apresenta os resultados obtidos para a composição físico-química do leite de búfala. Os teores de sólidos totais, proteína e sais minerais mostraram-se similares aos encontrados por Akgun, Yazici e Gulec (2016). Entretanto, quanto ao teor de lipídeos foram diferentes dos determinados por Akgun, Yazici e Gulec (2016) e Fonseca et al. (2016). Fagnani et al. (2014) relataram que o teor de lipídeos é um dos componentes mais variáveis no leite. Além da sazonalidade, estes autores verificaram que a raça, a alimentação e o estágio de lactação também modificam o teor de lipídeos. Eles também concluíram que todas essas variáveis são responsáveis pelas divergências encontradas entre diferentes pesquisas. É importante salientar que não há uma legislação específica para determinar o padrão de identidade e qualidade do leite de búfala, e que segundo Amaral et al. (2005) o Estado de São Paulo é o único que estabelece como parâmetro de qualidade para este tipo de leite valores mínimos para o teor de gordura iguais a $4,5 \mathrm{~g} / 100 \mathrm{~g}$. 
Recebido em:

$19 / 06 / 2018$

Aceito em:

$09 / 10 / 2018$

Tabela 1 - Resultados médios \pm desvio padrão para os parâmetros físicos e químicos do leite de búfala.

\begin{tabular}{lc}
\hline Parâmetros & Resultados \\
\hline Sólidos totais $(\mathrm{g} / 100 \mathrm{~g})$ & $15,04 \pm 0,22$ \\
Proteína $(\mathrm{g} / 100 \mathrm{~g})$ & $4,50 \pm 0,05$ \\
Lipídeos $(\mathrm{g} / 100 \mathrm{~g})$ & $4,93 \pm 0,32$ \\
Sais minerais $(\mathrm{g} / 100 \mathrm{~g})$ & $0,98 \pm 0,01$ \\
$\mathrm{pH}$ & $6,59 \pm 0,06$ \\
Acidez titulável $(\mathrm{g}$ de ácido lático/100g) & $0,18 \pm 0,01$ \\
\hline
\end{tabular}

Fonte: elaborado pelo autor (2018).

Para o teor de sais minerais os valores encontrados por Verruma e Salgado (1994) foram iguais a $0,70 \mathrm{~g} / 100 \mathrm{~g}$. Assim como a gordura, o teor de sais minerais do leite de búfala avaliado também foi diferente do apresentado pela literatura, sendo que neste caso, Bailone et al. (2017) afirmam que é influenciado principalmente pelo estágio de lactação.

A Secretaria de Agricultura e Abastecimento (SAA) do Estado de São Paulo publicou uma resolução válida para este estado, onde estabelece também valores de $\mathrm{pH}$ (entre 6,40 e 6,90) e acidez entre 0,18 e 0,23 g/100g de ácido lático para caracterização de leite búfala (DELA RICCI; DOMINGUES, 2012). Assim, pode-se verificar que os valores encontrados para o leite de búfala estão dentro do estabelecido por esta legislação. Dela Ricci e Domingues (2012) afirmam que a acidez titulável do leite da búfala apresenta valores ligeiramente superiores à acidez titulável do leite de vaca, provavelmente em função da maior quantidade, diâmetro e número das micelas de caseína, quando comparado ao leite da vaca.

\subsection{Caracterização física e química do doce de leite}

$\mathrm{Na}$ Tabela 2 encontram-se os resultados obtidos para as análises físico-químicas das amostras dos doces de leite de búfala (B1 e B2). Silva et al. (2015) afirmam que o maior rendimento de doces de leite está relacionado à menor perda de massa durante as suas etapas de elaboração.

Os teores de sólidos solúveis totais não diferiram $(\mathrm{P}>0,05)$ entre as amostras de doce elaboradas, no entanto, os valores obtidos foram similares aos indicados por Giménez, Ares e Gámbaro (2008) para a elaboração de doce de leite com padrão aceitável por consumidores regulares deste tipo de produto, ou seja, entre 70 e $74^{\circ}$ Brix.

A aceitabilidade de um doce de leite pelos consumidores também está relacionada com os valores de $\mathrm{pH}$ e acidez. Gaze et al. (2015) observaram para doces de leite comerciais variações nos valores do $\mathrm{pH}$ (entre 6,14 e 6,37) e acidez (entre 0,23 e 0,50 g de ácido lático/100g). Os valores de $\mathrm{pH}$ obtidos para as amostras B1 e B2 apresentarem pequena diferença $(\mathrm{P}<0,05)$, sendo que o pH da amostra B2 foi menor $(\mathrm{P}<0,05)$. De acordo com Pastoriza, Quesada e Rufián-Henares (2018) durante a reação de Maillard, o pH é reduzido, tanto pela produção de ácidos como pela conversão de aminas em compostos de nitrogênio cíclico, embora essas mudanças sejam neutralizadas em certa medida pela perda de dióxido de carbono. Assim, também de acordo com estes autores, durante a reação de Maillard, no doce de leite elaborado 
Recebido em:

$19 / 06 / 2018$

Aceito em:

$09 / 10 / 2018$

com substituição parcial de sacarose por oligofrutose, o decaimento do $\mathrm{pH}$ pode ter sido devido a maior liberação de água e dióxido de carbono. Gaze et al. (2015) também citam que a faixa de pH entre 6 e 7, iria contribuir para o não surgimento de grumos no doce de leite, e pelo surgimento da cor marrom produzida pela reação de Maillard. Gaze et al. (2015) citam também que os valores para a acidez ideais em ácido lático de doce de leite bovino ficaria entre 0,23 e 0,50 $\mathrm{g} / 100 \mathrm{~g}$.

Tabela 2 - Resultados para a composição físico-química dos doces de leite de búfala elaborados (B1 e B2), sendo que a amostra B2 foi a que apresentou substituição parcial de sacarose pela oligofrutose (10\%).

\begin{tabular}{lll}
\hline Parâmetros & Doce de Leite B1 & Doce de Leite B2 \\
\hline Rendimento $(\%)$ & 38,30 & 39,80 \\
Sólidos solúveis totais $\left({ }^{\circ}\right.$ Brix $)$ & $70,70^{\mathrm{a}} \pm 0,20$ & $71,45^{\mathrm{a}} \pm 0,55$ \\
$\mathrm{pH}$ & $6,95^{\mathrm{a}} \pm 0,01$ & $6,77^{\mathrm{b}} \pm 0,03$ \\
Acidez $(\mathrm{g} / 100 \mathrm{~g}$ de ácido lático) & $0,24^{\mathrm{a}} \pm 0,01$ & $0,27^{\mathrm{a}} \pm 0,02$ \\
Umidade $(\mathrm{g} / 100 \mathrm{~g})$ & $27,65^{\mathrm{a}} \pm 0,14$ & $27,72^{\mathrm{a}} \pm 0,20$ \\
Atividade de água & $0,78^{\mathrm{a}} \pm 0,01$ & $0,79^{\mathrm{a}} \pm 0,01$ \\
Sais minerais $(\mathrm{g} / 100 \mathrm{~g})$ & $2,15^{\mathrm{a}} \pm 0,06$ & $2,11^{\mathrm{a}} \pm 0,04$ \\
\hline
\end{tabular}

Média \pm desvio padrão, com letras minúsculas diferentes sobrescritas na mesma linha indicam diferenças significativas $(\mathrm{P}<0,05)$ entre as amostras.

Fonte: elaborado pelo autor (2018).

Em relação ao teor de umidade, as duas amostras de doce de leite de búfala também não apresentaram diferenças ( $\mathrm{P}>0,05)$, e neste caso os valores estão de acordo com Brasil (1997) para doce de leite de vaca, que estipula valor máximo igual a $30 \mathrm{~g} / 100 \mathrm{~g}$. Gallina, Rogalsky e Alves (2009) avaliaram o teor de sólidos totais para 30 amostras comerciais de doce de leite bovino e, observaram uma variação entre 73,06 g/100g e 73,77 g/100g. Estes valores não foram muito diferentes dos obtidos no presente estudo cujos teores de sólidos totais médios ficaram entre $72,28 \mathrm{~g} / 100 \mathrm{~g}$ e $72,35 \mathrm{~g} / 100 \mathrm{~g}$, para o doce de leite obtido com substituição parcial da sacarose (amostra B) e o doce de leite elaborado com sacarose (amostra A), respectivamente. Assim como a umidade e os sólidos totais, não foi notada diferença $(\mathrm{P}>0,05)$ entre os valores da atividade de água das amostras B1 e B2. Ferreira et al. (2012), relatam que a presença de microrganismos deteriorantes é diminuída quando os valores para a atividade de água estão abaixo de 0,90 .

Os teores de sais minerais das amostras B1 e B2 foram maiores do que o indicado por Brasil (1997) para doce de leite, cujo teor recomendado é de no máximo 2,0 g/100g. Entretanto, Gaze et al. (2015) creditam aumentos para os teores de sais minerais do doce de leite à adição do bicarbonato de sódio. Segundo estes autores, estes compostos, mesmo adicionados em pequenas quantidades no doce de leite, podem contribuir para o aumento nos teores de sais minerais.

\subsubsection{Análise de cor}


Recebido em:

$19 / 06 / 2018$

Aceito em:

$09 / 10 / 2018$

A Tabela 3 apresenta os valores obtidos para os parâmetros $L^{*}$ e $b^{*}$ das amostras de doce de leite de búfala (B1 e B2). Vale ressaltar que o valor de $\mathrm{L}^{*}$ indica a luminosidade, ou seja, quanto mais próximo de 100, mais clara é a amostra. Assim, observou-se que a amostra B1 foi mais clara $(\mathrm{P}<0,05)$ do que a B2, ou seja, a que empregou oligofrutose. De acordo com Mensink et al. (2015), a oligofrutose pode participar de reações com outros componentes, como o grupo amino das proteínas na reação de Maillard. Desta forma, quando grupos redutores estiverem presentes a reação de Maillard pode ocorrer com maior facilidade, como foi observado na amostra B2, ou seja, o doce de leite bubalino elaborado com a substituição parcial da sacarose pela oligofrutose. O mesmo comportamento foi verificado por Costa et al. (2017) que creditaram à presença de oligofrutose à cor mais escura de suco de laranja probiótico. De acordo com Dattatreya e Rankin (2006), o parâmetro b* está relacionado com a fase intermediária da reação de Maillard, e assim à predominância da cor amarela. Como Silva et al. (2015), verificou-se que os dois doces elaborados apresentaram igualmente $(P>0,05)$ predominância da cor amarela, em decorrência dos valores positivos determinados para o parâmetro $b^{*}$.

Tabela 3 - Parâmetros de cor L* e b* das amostras de doce de leite de búfala sem (B1) ou com substituição parcial da sacarose por oligofrutose (10\%) (B2).

\begin{tabular}{lll}
\hline Parâmetros & Doce de Leite B1 & Doce de Leite B2 \\
\hline $\mathrm{L}^{*}$ & $61,98^{\mathrm{a}} \pm 4,66$ & $54,61^{\mathrm{b}} \pm 0,87$ \\
$\mathrm{~b}^{*}$ & $18,46^{\mathrm{a}} \pm 0,35$ & $18,37^{\mathrm{a}} \pm 1,51$ \\
\hline
\end{tabular}

Média \pm desvio padrão, com letras minúsculas diferentes sobrescritas na mesma linha indicam diferenças significativas $(\mathrm{P}<0,05)$ entre as amostras.

Fonte: elaborado pelo autor (2018).

\subsubsection{Análise do perfil de textura}

Os resultados para os parâmetros de textura avaliados nos dois doces de leite de búfala elaborados encontram-se na Tabela 4. Vale ressaltar que Szczesniak (2001) define a firmeza como a força necessária para comprimir alimentos semissólidos, como o doce de leite, entre a língua e o palato. A elasticidade é a facilidade da amostra em recuperar a forma após ser submetida a uma força, enquanto a adesividade seria a força exigida para remover o material aderido à boca durante o seu consumo. Em relação à gomosidade esta seria a energia necessária para dissolver uma porção do alimento semissólido em um estado pronto para engolir (SZCESNIAK, 2001). Assim, pode-se verificar que o doce de leite com oligofrutose (B2) apresentou maiores valores $(\mathrm{P}<0,05)$ para firmeza, adesividade e gomosidade do que a amostra elaborada com sacarose (B1). Francisquini et al. (2016) também observaram grande variação nos parâmetros entre o perfil de textura de doces de leites comerciais. Gomes et al. (2007) também verificaram o aumento da firmeza em produtos com oligofrutose. 
Recebido em:

$19 / 06 / 2018$

Aceito em:

$09 / 10 / 2018$

Tabela 4 - Resultados médios \pm desvio padrão para os parâmetros firmeza, elasticidade, adesividade e gomosidade dos doces de leite de búfala sem e com o emprego da oligofrutose (10\%) na substituição parcial de sacarose.

\begin{tabular}{lll}
\hline Parâmetros & Doce de Leite B1 & Doce de Leite B2 \\
\hline Firmeza (N) & $2,48^{\mathrm{b}} \pm 0,55$ & $3,70^{\mathrm{a}} \pm 0,39$ \\
Elasticidade & $86,74^{\mathrm{a}} \pm 3,91$ & $90,56^{\mathrm{a}} \pm 0,38$ \\
Adesividade (N.s) & $9,17^{\mathrm{b}} \pm 0,63$ & $22,12^{\mathrm{a}} \pm 0,13$ \\
Gomosidade (N) & $1,84^{\mathrm{b}} \pm 0,36$ & $2,68^{\mathrm{a}} \pm 0,30$ \\
\hline
\end{tabular}

Média \pm desvio padrão, com letras minúsculas diferentes sobrescritas na mesma linha indicam diferenças significativas $(\mathrm{P}<0,05)$ entre as amostras.

Fonte: elaborado pelo autor (2018).

Mendenhall e Hartel (2016) ressaltaram que durante o aquecimento de sistemas lácteos concentrados, contendo sacarose ou outros tipos de ingredientes, ocorre a gelificação térmica das proteínas do leite. Através do aquecimento, em temperaturas mais altas, ou seja, quando o produto começa a entrar em ebulição, esta gelificação é mais difícil de controlar, principalmente quanto mais tipos de sólidos não gordurosos estiverem presentes (MENDENHALL; HARTEL, 2016). Enfim, este estudo apresentou relevância não somente visando a aceitação pelos consumidores, mas também é importante para a escolha da embalagem, no armazenamento e na aplicação futura do doce de leite bubalino em outros produtos.

\section{CONCLUSÃ̃O}

O caráter inovador na elaboração de doce de leite bubalino semissólido com substituição parcial de $10 \%$ de sacarose por $10 \%$ oligofrutose (um prebiótico) contribuiu para a obtenção de um produto com maior rendimento; com $\mathrm{pH}$ mais alto; mais escuro; mais firme e adesivo; requerendo maior gasto de energia para ser consumido. Com isto, estes resultados poderão ser empregados visando à diversificação de produtos lácteos bubalino.

\section{REFERÊNCIAS}

AKGUN, A.; YAZICI, F.; GULEC, H. A. Effect of reduced fat content on the physicochemical and microbiological properties of buffalo milk yoghurt. LWT - Food Science and Technology, [s.1]., v. 74, p. 521-527, 2016.

AMARAL, F. R. et al. Qualidade do leite de búfalas: composição. Revista Brasileira de Reprodução Animal, Belo Horizonte, v.29, p.106-110, 2005.

ASSOCIATION OF OFFICIAL ANALYTICAL CHEMISTS (AOAC). Official Methods of Analysis of the Association Analytical Chemists, 18th ed. AOAC, Gaithersburg, MD, USA, 2005. 
BAILONE, R. L. et al. Quality of refrigerated raw milk from buffalo cows (Bubalus bubalis) in different farms and seasons in Brazil. Ciência Animal Brasileira, [s.1], v.18, p.1-12, 2017.

BRASIL, Ministério da Agricultura, Pecuária e Abastecimento. Departamento de Inspeção de Produtos de origem Animal. Portaria n. 354, de 04 de setembro de 1997. Regulamento Técnico para Fixação de Identidade e Qualidade de Doce de Leite. Diário Oficial da União, Brasília DF, 1997.

BRASIL. Ministério da Agricultura, Pecuária e Abastecimento. Secretaria de Defesa Agropecuária. Departamento de Saúde Animal. Dados de rebanho bovino e bubalino no Brasil - 2017. Disponível em: http://www.agricultura.gov.br/assuntos/sanidade-animal-e-vegetal/saudeanimal/programas-de-saude-animal/febre-aftosa/documentos-febreaftosa/DadosderebanhobovinoebubalinodoBrasil_2017.pdf. Acesso em: 04 out. 2018.

BUZI, K. A. et al. Análise microbiológica e caracterização eletroforética do queijo mussarela elaborado a partir de leite de búfala. Ciência e Tecnologia de Alimentos, [s.1], v. 29, p. 07-11, 2009.

COSTA, G. M. et al. Effect of ascorbic acid or oligofructose supplementation on L. paracasei viability, physicochemical characteristics and acceptance of probiotic orange juice. LWT - Food Science Technology. [s.1], v.75, p.195-201, 2017.

DATTATREYA, A.; RANKIN, S. A. Moderately acidic $\mathrm{pH}$ potentiates browning of sweet whey powder. International Dairy Journal. v.16, p.822-828, 2006.

DELA RICCI, G.; DOMINGUES, P. F. Grandes animais, o leite de búfala. Revista de Educação Continuada em Medicina Veterinária e Zootecnia do CRMV-SP, [s.1], v.10, p.14-19, 2012.

DEMIATE, I. M; KONKEL, F.E; PEDROSO, R. A. Avaliação da qualidade de amostras comerciais de doce de leite pastoso - composição química. Revista Ciência e Tecnologia de Alimentos, [s.1], v.21, n.1, 2001.

FAGNANI, R. et al. Parâmetros físico-químicos e microbiológicos do leite em função da sazonalidade. Revista do Instituto de Laticínios Cândido Tostes, [s.1], v.69, p.173, 2014.

FERREIRA, L. O. et al. Avaliação das características de qualidade de doces de leite comerciais. Revista do Instituto de Laticinios Candido Tostes, [s.1], v.67, n.387, p.05-11, 2012.

FONSECA, C. R. et al. Leites de outras espécies: búfala, cabra e ovelha. In: CRUZ, A. G. et al. (Eds.). Quimica, Bioquimica, Análise Sensorial e Nutrição no Processamento de Leite e Derivados. 1. ed. Rio de Janeiro: Elsevier, 2016.

FRANCISQUINI, A. J. et al. Avaliação da intensidade da reação de Maillard, de atributos físicoquímicos e análise de textura em doce de leite, Revista Ceres, [s.1], v.1, p.589-596, 2016. 
GALLINA, D.A.; ROGALSKY, A. D.; ALVES, A. T. S. Comparação de métodos para determinação do extrato seco total em doce de leite pastoso. Revista do Instituto de Laticínios Cândido Tostes, [s.1], v. 64, n. 370, p. 10-13, 2009.

GAZE, L. V. et al. Preference mapping of dulce de leche commercialized in Brazilian markets. Journal of Dairy Science, [s.l], v.98, p.1443-1454. 2015.

GIMENEZ, A.; ARES, G.; GÁMBARO, A. Consumer reaction to changes in sensory profile of dulce de leche due to lactose hydrolysis. International Dairy Journal, [s.1], v.18, p.951-955, 2008.

GOMES, C. R. et al. Influência de diferentes agentes de corpo nas características reológicas e sensoriais de chocolates diet em sacarose e light em calorias. Ciência e Tecnologia de Alimentos, v.27, p.614-623, 2007.

IDF. International Dairy Federation. The World Dairy Situation 2012. Bulletin of the IDF $\mathbf{n}^{\mathbf{0}} \mathbf{. 4 5 8 / 2 0 1 2}, 2012.235 \mathrm{p}$.

MENDENHALL, H.; HARTEL, R. W. Effects of fat content and solid fat content on caramel texture attributes. Journal of the American Oil Chemists' Society, [s.l], v.93, p.1191-1199, 2016.

MENSINK, M. A. et al. Inulin, a flexible oligosaccharide I: Review of its physicochemical characteristics. Carbohydrate Polymers, [s.1], v.130, p.405-419. 2015.

OLIVEIRA, A. C. P. et al. Parâmetros industriais da produção de doce de leite. Revista do Instituto de laticínios Cândido Tostes, [s.l], v. 71, n. 3, p. 179-185, 2016.

PASTORIZA, S.; QUESADA, J.; RUFÍAN-HENARES, J.A. Lactose and oligosaccharides: maillard reaction. Reference Module in Food Science, [s.1], p. 1-19, 2018.

PATIÑO, E. M. Leite de búfalas. In: JORGE, A. M.; COUTO, A. G.; CRUDELI, G. A.; E. M. (Eds.). Produção de búfalas de leite. Botucatu: FEPAF, p.79-108, 2011.

PIERETTI, G. G.; SEOLLIN, V. J.; BENTO, R. S. Doce de leite pastoso elaborado com açúcar mascavo: dulce de leche prepared with brown sugar, sensory, physicochemical and microbiological evaluation, Revista do Instituto Laticinios Cândido Tostes, [s.1], n. 390, v.68, p.59-64, 2012.

SILVA, F.L. et al. Production of dulce de leche: the effect of starch addition. Food Science and Technology, [s.1], v.62, p.417-423, 2015. 
SZCZESNIAK, A. S. Texture is a sensory property. Food Quality and Preference, [s.1], v.13, p.215-225, 2001.

IAL (INSTITUTO ADOLFO LUTZ). Métodos físico-químicos para análise de alimentos. 4 ed. São Paulo: IAL, 2008. 1018p.

SENO, L. O.; CARDOSO, V. L.; TONHATI, H. Valores econômicos para as características de produção de leite de búfalas no Estado de São Paulo. Revista Brasileira de Zootecnia, v. 36, n. 6 suppl, p. 2016-2022, 2007.

VERRUMA, M. R.; SALGADO, J. M. Análise química do leite de búfala em comparação ao leite de vaca. Scientia Agricola, [s.1], v. 51, p. 131-137, 1994.

VIEIRA, M. C. et al. Produção de doce de leite tradicional, light e diet: estudo comparativo de custos e viabilidade econômica. Informações Econômicas, [s.1], v. 41, n. 10, p. 15-27, 2011.

YÁÑEZ et al. Antioxidant activity developed at the different stages of Maillard reaction with milk proteins. LWT - Food Science and Technology, [s.1], v. 89, p. 344-349, 2018. 